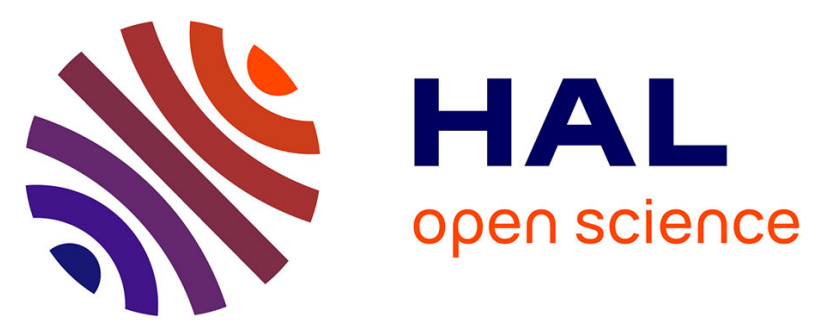

\title{
Interfacial Engineering through Chloride-Functionalized Self-Assembled Monolayers for High-Performance Perovskite Solar Cells
}

\author{
Tao Zhu, Jun Su, Frédéric Labat, Ilaria Ciofini, Thierry Pauporte
}

\section{- To cite this version:}

Tao Zhu, Jun Su, Frédéric Labat, Ilaria Ciofini, Thierry Pauporte. Interfacial Engineering through Chloride-Functionalized Self-Assembled Monolayers for High-Performance Perovskite Solar Cells. ACS Applied Materials \& Interfaces, 2019, 12 (1), pp.744-752. 10.1021/acsami.9b18034 . hal-02572307

\section{HAL Id: hal-02572307 https://hal.science/hal-02572307}

Submitted on 13 May 2020

HAL is a multi-disciplinary open access archive for the deposit and dissemination of scientific research documents, whether they are published or not. The documents may come from teaching and research institutions in France or abroad, or from public or private research centers.
L'archive ouverte pluridisciplinaire HAL, est destinée au dépôt et à la diffusion de documents scientifiques de niveau recherche, publiés ou non, émanant des établissements d'enseignement et de recherche français ou étrangers, des laboratoires publics ou privés. 


\section{Cite this paper as:}

T. Zhu, J. Su, F. Labat, I. Ciofini, Th. Pauporté, ACS Appl. Mater Interfaces, 2020, 12, 744-752.

DOI: $10.1021 /$ acsami.9b18034

\section{Interfacial Engineering through Chloride-Functionalized}

\section{Self-Assembled Monolayer for High-Performance \\ Perovskite Solar Cells}

Tao Zhu, ${ }^{[a]}$ Jun Su, ${ }^{[b]}$ Frédéric Labat, ${ }^{[b]}$ Ilaria Ciofini, ${ }^{[b]}$ and Thierry Pauporté ${ }^{*[a]}$

[a] Chimie ParisTech, PSL Research University, CNRS, Institut de Recherche de Chimie Paris (IRCP), 11 rue P. et M. Curie, F-75005 Paris, France. *Corresponding author, e-mail: thierry.pauporte@chimieparistech.psl.eu

[b] Chimie ParisTech, PSL Research University, CNRS, Institute of Chemistry for Life and Health sciences (i-CLeHS), 11 rue P. et M. Curie, F-75005 Paris, France.

KEYWORDS: Hydrides; Self-assembled monolayers; Perovskite solar cells; Benzoic acid derivatives; High efficiency; Density functional theory. 
ABSTACT: The family of organic-inorganic hybrid perovskite (OIHPs) materials is one of the most promising for very high efficiency photovoltaic solar cells application. In the present work, the effect of a series of self-assembled monolayers placed at the $\mathrm{TiO}_{2}$-perovskite junction, on the functioning of triple cation perovskite solar cells has been investigated. We show that employing 4-chlorobenzoic acid leads to the marked boosting of the solar cells performances. The starting pristine cell had a $20.3 \%$ power conversion efficiency (PCE) and the chemical engineering permitted to reach a PCE up to $21.35 \%$. Our experimental study completed by density functional theory (DFT) calculations and modelling show that this improvement is due to the reduction of interfacial states, to the improvement of the quality of the OIHP material and to the structural continuity between $\mathrm{TiO}_{2}$ and the OIHP. Especially, we demonstrate that the interfacial chemical interactions are important to consider in the design of highly efficient devices.

\section{Introduction}

Recently, organic-inorganic hybrid perovskites (OIHPs) have emerged as one of the most promising family of materials for applications in various fields such as lasers, LED, photodetectors, scintillation and photovoltaic solar cells. ${ }^{1-14}$ This material family exhibits excellent optoelectronic properties, tunable bandgap, long charge carrier lifetime, low cost and low-temperature solution processibility. OIHPs thin films can be printed on flexible substrates for lightweight devices. The record power conversion efficiency of perovskite solar cells (PSCs) has increased rapidly and continuously during the last decade and is now certified at $25.2 \%{ }^{15}$ PSCs are presently the most performant thin film solar cell technology and they are close to the efficiency of the best silicon technology. 
In the most popular direct structure, a $\mathrm{TiO}_{2}$ mesoporous layer is deposited on top of a $\mathrm{TiO}_{2}$ hole blocking layer. ${ }^{16}$ The OIHP absorber film is grown on top of these layers and is covered by a p-type molecular semiconductor, typically Spiro-OMeTAD. In the inverted cell structure, the OIHP layer is deposited on top of the p-type selective contact. The oxide n-type semiconductor layer blocks the hole transfer and ensures the electron transport. ${ }^{16}$ The injection of the photogenerated electrons is a key step in the photovoltage and photocurrent generation. High efficiency requires a high quality of the interfaces and correct energy band matchings between the various layers. Engineering the interfaces with facile solution-based processes is an attractive means to boost the PSC functioning and performances. Self-assembled monolayers (SAMs) are very interesting for this purpose. SAMs of organic compounds have been implemented in PSC interfaces and they can potentially induce various positive effects. (i) They can influence the morphology of the perovskite layer, favor the crystallinity, the grain size and the absence of pinholes in the absorber material. (ii) Organized and aligned SAMs of polar molecules produce a permanent molecular dipole moment normal to the surface. This polar layer changes the work function and generates an electric field that can favor the extraction of the photogenerated charges from the perovskite layer. (iii) SAMs can passivate the trap states on the oxide selective contact; (iv) they can also passivate trap states in the perovskite layer. (v) They can delay the charge recombination and act as an insulating layer. ${ }^{17}$ (vi) SAMs can also act as barrier between perovskite and the underlayer and avoid them to react each other. ${ }^{18,19}$

Recent results illustrate the interest of applying SAMs to PSCs. ${ }^{20-22}$ For instance, Li et al. ${ }^{23}$ introduced the 4-aminobenzoic acid at the interface between $\mathrm{TiO}_{2}$ and $\mathrm{CH}_{3} \mathrm{NH}_{3} \mathrm{PbI}_{3}$ (MAPI). Their PSCs had a poor efficiency but the treatment was beneficial to the performances. Zuo et al. $^{24}$ applied C3-SAMs to planar solar cells based on $\mathrm{ZnO}$ electron transporting layer (ETL). The 
interfacial engineering improved the MAPI layer morphology and passivated the trap states. Moreover, the authors claimed a better energy level alignment due to the reduction of the work function of the $\mathrm{ZnO}$ ETL (dipole moment of the $\mathrm{C} 3$ molecule). More recently, $\mathrm{ZnO}$ was engineered by a dual-functional SAM. ${ }^{25}$ The treated cells achieved a $18.8 \%$ PCE. Wang et al. ${ }^{26}$ explored the effect SAMs on NiO-based inverted structure PSCs. They found that 4bromobenzoic acid effectively passivates the surface. It reduced the trap-assisted recombination, improved the surface wettability and minimized the energy offset between $\mathrm{NiO}$ and MAPI perovskite. $\beta$-alanine was also employed in inverted structures. The amino group was attached to PEDOT-PSS while carbonyl terminal group interacted with MAPI. The dipole moment of the molecular interface modifier favored the charge extraction. ${ }^{27}$ Palomares et al. directly used SAMs to replace the commonly used PEDOT:PSS contact layer and reached an efficiency of $17.3 \%$ in inverted structure MAPI PSCs. ${ }^{28}$ In the present literature on PSC, most SAMs employed feature $\mathrm{C} 60$, amine or ammonium groups. ${ }^{19}$ Will et al. reported that the interfacial chemical composition can be controlled from Pb-poor to Pb-rich by the SAMs. ${ }^{27}$ Also SAMs have been investigated on the top of the perovskite layer. ${ }^{29}$ It has been shown that thiol group form firm coordination with the perovskite. ${ }^{30,31}$ Hydrophobic molecular SAMs have been used notably to protect OIHP from moisture and increase the device durability. ${ }^{30-33}$

In the present work, the effect of SAM interfaces on the functioning of triple cation perovskite solar cells has been studied. A series of acids with a benzene spacer and various functional (terminal) groups have been tested. By varying the functional group, the strength and sign of their molecular dipole moment have been monitored over a wide range. Moreover, the data have been completed by the study of $\beta$-alanine ( $\beta$-ALA). In these molecules, $-\mathrm{COO}$ was the anchoring group, permitting the SAMs formation and attachment onto $\mathrm{TiO}_{2}$ in a bridging 
bidentate mode. We show that employing SAMs with a chloride functional group leads to the marked boosting of the triple cation perovskite solar cells performances. The starting pristine cells had high performances (PCE up to 20.3\%) but the interfacial engineering permitted to reach a PCE up to $21.35 \%$ (stabilized at $20.9 \%$ ). Our experimental and theoretical study shows that this improvement is due to the reduction of interfacial states, to the improvement of the quality of the OIHP material and to the structural continuity between $\mathrm{TiO}_{2}$ and the OIHP. To our knowledge, it is the first time that chloride terminated SAMs are shown to boost the efficiency of PSC and that acid modified interface PSCs achieve an efficiency higher than $21 \%$.

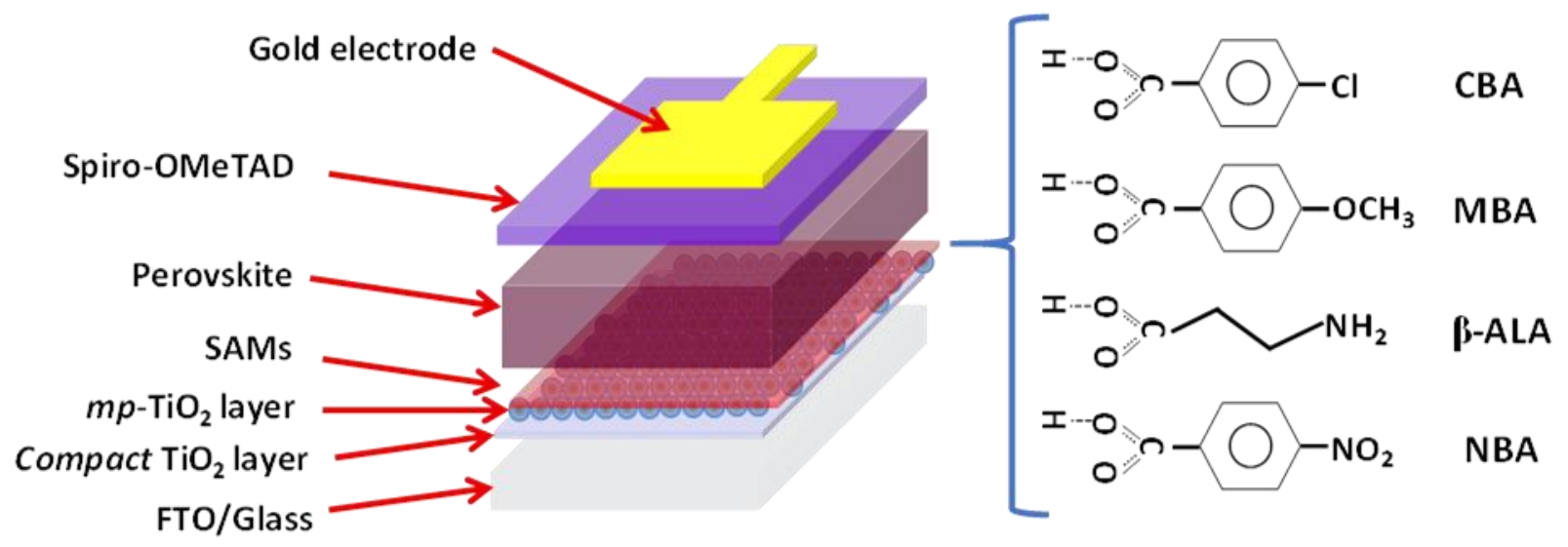

Figure 1. Schematic presentation of the investigated mesoscopic perovskite solar cells. The mesoporous $m p-\mathrm{TiO}_{2}$ layer was covered by SAMs (in red) of various para-substituted benzoic acids and $\beta$-alanine before to be covered by the Cs8FAMA perovskite layer.

\section{Results}

The schematic device structure is presented in Figure 1 and the SEM cross-section is displayed in Figure S1a (Supporting Information). The perovskite absorber employed was a hybrid perovskite, mixing three monovalent cations with $\mathrm{Cs}_{0.08} \mathrm{FA}_{0.80} \mathrm{MA}_{0.12} \mathrm{~Pb}\left(\mathrm{I}_{0.88} \mathrm{Br}_{0.12}\right)_{3}$ as a general formula (hereafter noted Cs8FAMA). The FTO/glass substrate was covered by a 
compact and pinhole-free $\mathrm{TiO}_{2}$ film by using the spray pyrolysis technique $\left(\right.$ Compact- $\left.\mathrm{TiO}_{2}\right){ }^{16}$ This layer is important to get high performances by avoiding the direct contact between the perovskite and the FTO and blocking the transfer of holes. A $\mathrm{TiO}_{2}$ mesoporous layer $\left(m p-\mathrm{TiO}_{2}\right)$ was deposited by spin-coating on its top. The average thickness of this layer was 120-130 nm. Immediately after its annealing, the $m p-\mathrm{TiO}_{2}$ layer was treated with methanol solutions of various acids as described in the Experimental Section. The investigated acids were parasubstituted benzoic acid derivatives: 4-Chlorobenzoic acid (CBA), 4-methoxy benzoic acid (MBA) and 4-nitro benzoic acid (NBA). Additionally, $\beta$-alanine (also called 3-aminopropanoic acid and noted $\beta$-ALA), an amino-acid, was also investigated. The full study of 4-Bromo benzoic acid (BrBA) and 4-Amino benzoic acid (ACA) was discarded at early stage as explained in the Experimental Section. Figure S1b and S1c (Supporting Information) show the aspect of this layer before and after this treatment, respectively. The $m p-\mathrm{TiO}_{2}$ layer covers the substrate and forms a very open structure. The nanoparticle mean diameter was $30 \mathrm{~nm}$. The SEM images show that it had exactly the same aspect before and after the acid treatment. The treatment was effective because the rinsing step removed the reactant excess and only the molecules bound to the $\mathrm{TiO}_{2}$ surface remained. In a previous work, the attenuated total reflection (ATR-IR) technique $\mathrm{e}^{34-39}$ was employed to get information on the attachment of the four different acids on $\mathrm{TiO}_{2}{ }^{40}$ (see also the Supporting Information for details). We showed that the acids are robustly attached onto the $\mathrm{TiO}_{2}$ surface and that the attachment occurs in a bidendate bridging mode. This attachment configuration was confirmed by periodic DFT calculations. ${ }^{40}$ The modifiers form a selfassembled monolayer (SAM) at the surface of the mesoporous $\mathrm{TiO}_{2}$ layer. 


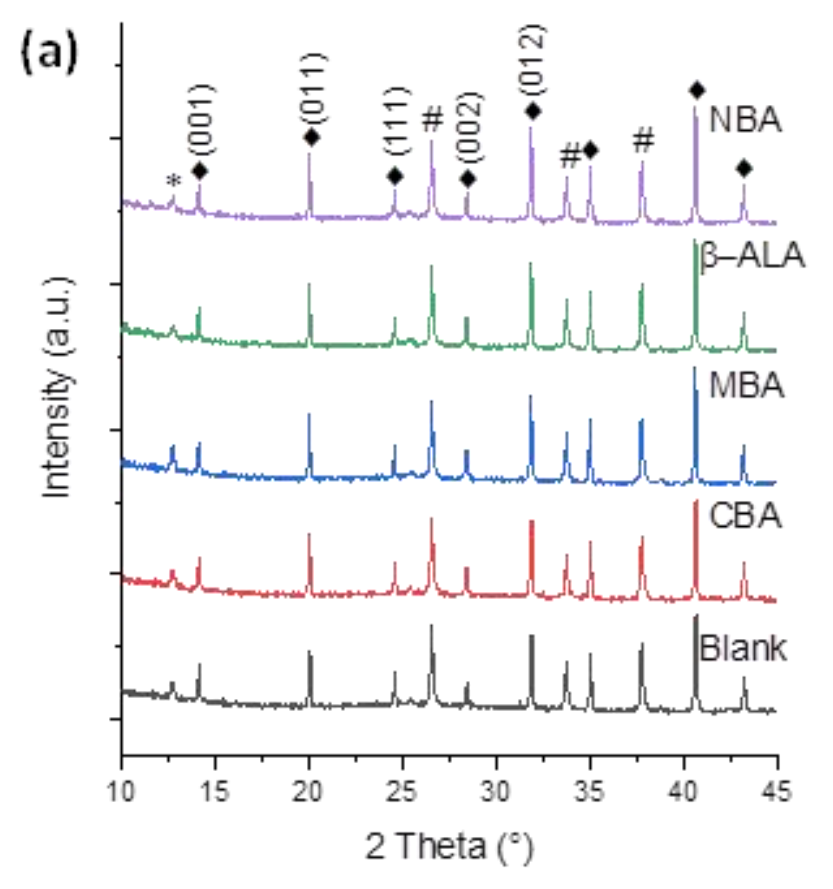

(b)
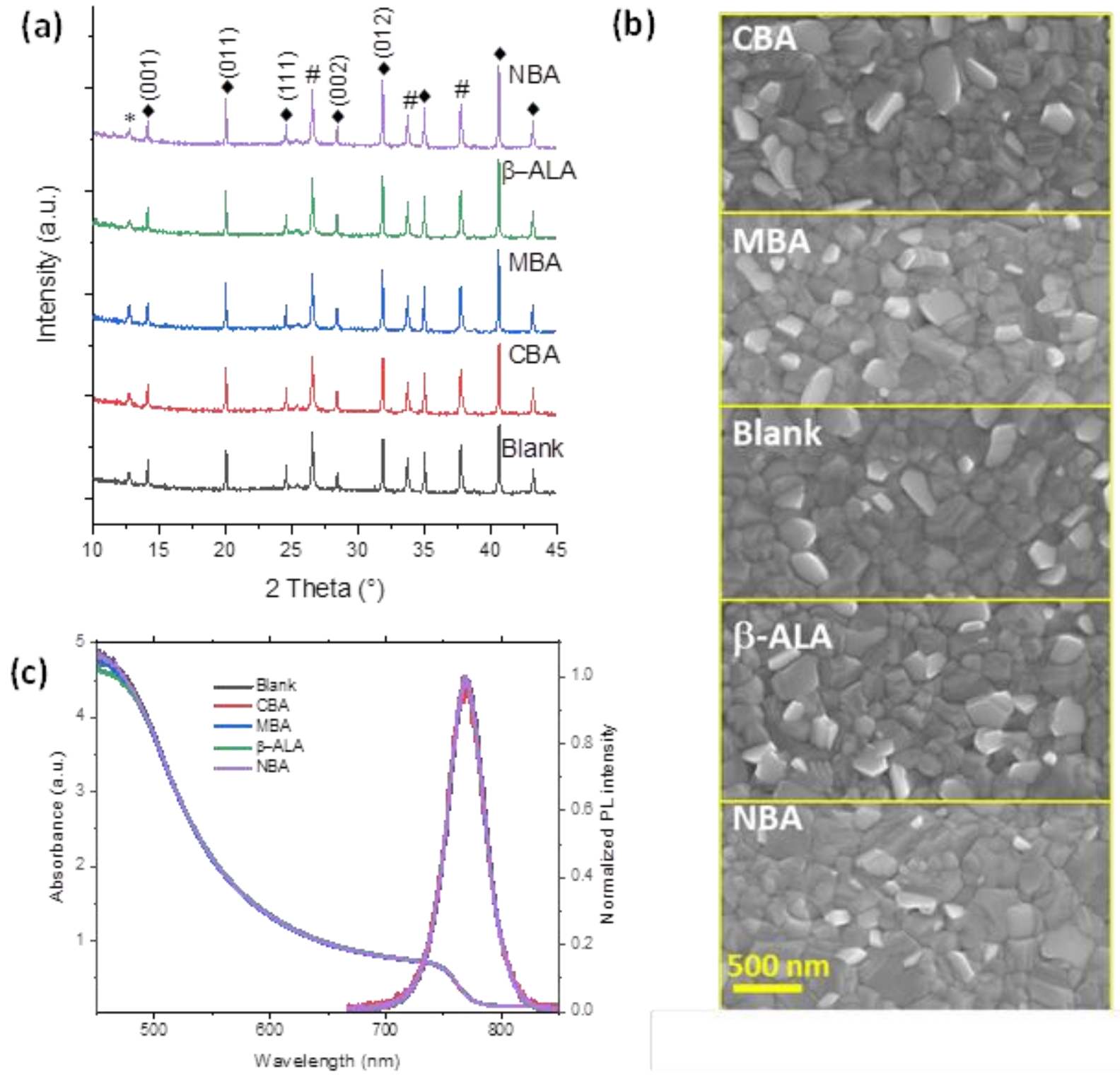

Figure 2. (a) XRD patterns of Cs8FAMA perovskite on pristine and acid-treated $\mathrm{TiO}_{2}$ underlayers. The peaks marked by \# are indexed to FTO. (b) FE-SEM top views of Cs8FAMA perovskite layers. (c) Absorbance and normalized photoluminescence of Cs8FAMA perovskite layers.

For the PSC preparation, a triple monovalent cation perovskite, Cs8FAMA, was employed. The crystallinity of the Cs8FAMA films prepared on pristine $\mathrm{TiO}_{2}$ and on the acid-modified 
$\mathrm{TiO}_{2}$ underlayers was investigated by $\mathrm{x}$-ray diffraction (XRD) ${ }^{41}$ In Figure $2 \mathrm{a}$, the characteristic peaks at $14.1^{\circ}, 20.0^{\circ}, 24.3^{\circ}, 28.4^{\circ}$ and $31.8^{\circ}$ are indexed to the (001), (011), (111), (002) and (012) crystal planes, respectively. ${ }^{42}$ The peaks present the same intensity and position for the various samples. They are also characterized by similar FWHMs. The FWHM of the (001), (011) and (002) peaks were measured at about $0.11^{\circ}, 0.09^{\circ}$ and $0.12^{\circ}$, respectively. From these similarities, we conclude that the SAMs presence and the chemical nature of the interfacial modifiers do not significantly influence the perovskite layer crystallinity. The broaden peak at 12. $7^{\circ}$ shows the presence of $\mathrm{PbI}_{2}$ impurity. It is noteworthy that more $\mathrm{PbI}_{2}$ is found in the MBA sample. The morphology of Cs8FAMA deposited on the various underlayers is compared in Figure $2 \mathrm{~b}$. The layers are perfectly covering and pinhole-free. They are made of well-crystallized grains with a size in the $210-280 \mathrm{~nm}$ range. No significant change in the grain shape, size and size dispersion could be observed on these views. Therefore, on the contrary to what was found for instance in the case of MAPI on a $\mathrm{NiO}$ underlayer, ${ }^{16}$ surface modifiers have no significant effect on the growth and crystallinity of the perovskite. The absorbance spectrum of the various perovskite samples is presented in Figure 2c. It is characterized by an absorption edge at 750-780 nm. The curves for Cs8FAMA on the pristine $\mathrm{TiO}_{2}$ and on the acid treated $\mathrm{TiO}_{2}$ overlap. It shows that the perovskite layer thickness is unchanged after the treatment with the various acids and that all the samples have the same perovskite thickness. The direct bandgap of Cs8FAMA is determined at $1.60 \mathrm{eV}$ and is independent of the interlayer chemical nature (Figure S3, Supporting Information). The normalized photoluminescence spectra are presented in Figure 2c. The spectra overlap and are centered at $770 \mathrm{~nm}$. 

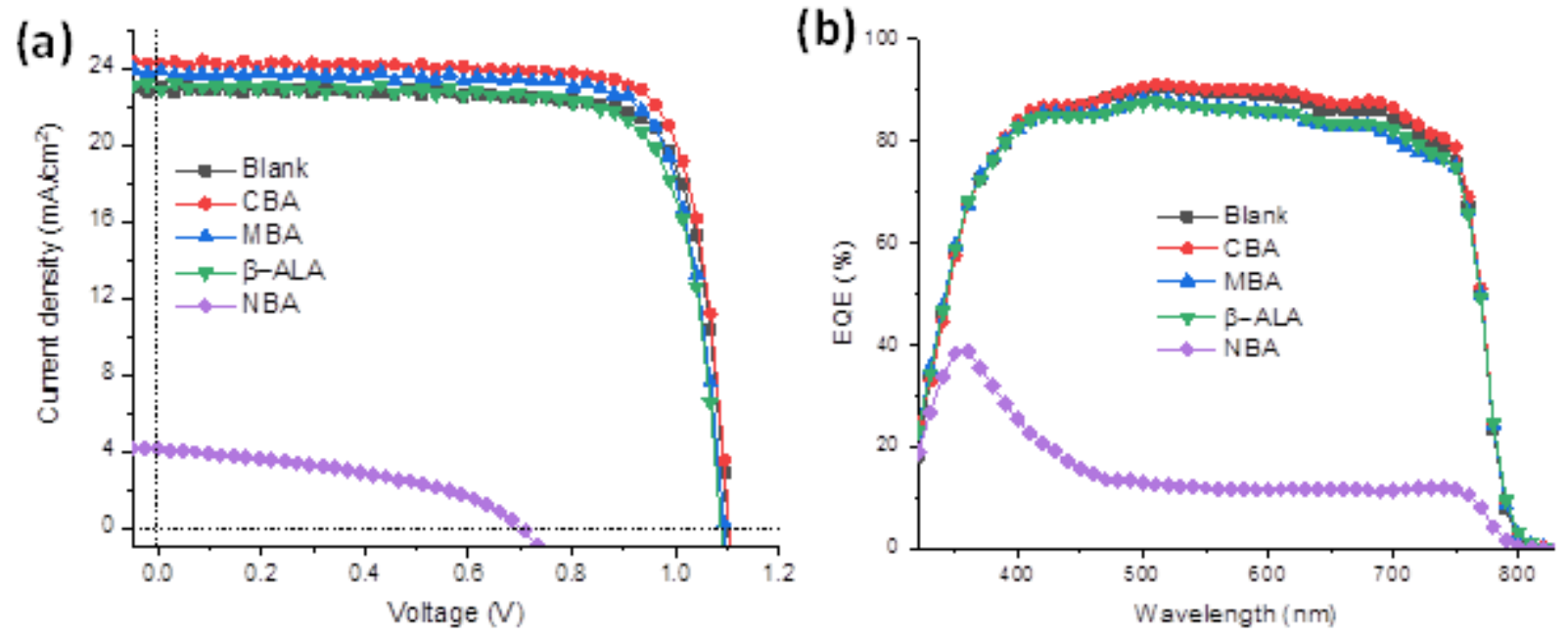

Figure 3. (a) Reverse scan $J-V$ curves and (b) EQE of PSCs engineered by various acids.

Table 1. Photovoltaic $J-V$ parameters of best Cs8FAMA cells.

\begin{tabular}{|c|c|c|c|c|c|c|}
\hline Cell & Scan direction & $V_{O C} / \mathbf{V}$ & $J_{S C} / \mathbf{m A} \cdot \mathbf{c m}^{-2}$ & $F F / \%$ & PCE / \% & $\mathrm{HI} / \%^{a}$ \\
\hline \multirow{2}{*}{ Blank } & Reverse & 1.110 & 23.29 & 78.53 & 20.30 & \multirow{2}{*}{6.6} \\
\hline & Forward & 1.105 & 23.27 & 73.81 & 18.97 & \\
\hline \multirow{2}{*}{ CBA } & Reverse & 1.101 & 24.25 & 79.81 & 21.35 & \multirow{2}{*}{12.9} \\
\hline & Forward & 1.086 & 24.26 & 70.59 & 18.60 & \\
\hline \multirow{2}{*}{ MBA } & Reverse & 1.094 & 23.87 & 79.29 & 20.73 & \multirow{2}{*}{19.3} \\
\hline & Forward & 1.068 & 23.85 & 65.70 & 16.73 & \\
\hline \multirow{2}{*}{$\beta$-ALA } & Reverse & 1.096 & 23.10 & 76.69 & 19.43 & \multirow{2}{*}{12.6} \\
\hline & Forward & 1.075 & 23.10 & 68.42 & 16.99 & \\
\hline \multirow{2}{*}{ NBA } & Reverse & 0.696 & 4.19 & 37.86 & 1.11 & \multirow{2}{*}{9.0} \\
\hline & Forward & 0.702 & 3.49 & 41.28 & 1.01 & \\
\hline
\end{tabular}

${ }^{\text {a }}$ Hysteresis index defined as: $H I(\%)=\frac{P C E_{r e v}-P C E_{\text {for }}}{P C E_{\text {rev }}}$

We have fabricated solar cells based on the device structure depicted in Figure 1 to investigate the effect of the $\mathrm{TiO}_{2}$ /perovskite interface engineering on the cell functioning and performances. ${ }^{14}$ The current-voltage $(J-V)$ curves of the best cells are presented in Figure 3 a and 
the data for the reverse and forward scans are gathered in Table 1. The performances varied significantly with the treatment. The blank cell achieved an efficiency of $20.3 \%\left(V_{\mathrm{OC}}=1.11 \mathrm{~V}\right.$, $\left.J_{\mathrm{SC}}=23.3 \mathrm{~mA} \cdot \mathrm{cm}^{-2}, \mathrm{FF}=78.5\right)$. Compared to the untreated cells, the CBA-Cs8FAMA devices presented much better performances. The highest efficiency achieved was $21.35 \%\left(V_{\mathrm{OC}}=1.10 \mathrm{~V}\right.$, $\left.J_{\mathrm{SC}}=24.25 \mathrm{~mA} \cdot \mathrm{cm}^{-2}, \mathrm{FF}=79.8\right)$. The performance of the MBA cell was close to the blank one. $\beta$ ALA cells were less efficient than the blank cell while this compound has been described in the literature to boost the PCE of various MAPI solar cells. ${ }^{24,29,43}$ NBA cells exhibited a very low efficiency. The presence of NBA SAMs deteriorated all the $J-V$ parameters, and the efficiency was very low. It this probable that this additive introduces trap states and defects at the interface which are at the origin of large parasitic charge recombination reaction. The EQE spectra are reported in Figure 3b. Excluding NBA, the EQE values are very high with the highest quantum efficiencies for the CBA cells, in good agreement with the superior $J_{\mathrm{SC}}$ for this device.

The statistical analysis of the performances in Figure 4 and the averaged values in Table S1 (Supporting Information) confirm the consistency of the trend. The PCE of the CBA cells is markedly superior to the blank due to higher $V_{\mathrm{OC}}$ and $J_{\mathrm{SC}}$ parameters. On the other hand, NBA is detrimental for the device functioning. The $J_{\mathrm{SC}}$ is very low with an average value at about 3 mA.cm ${ }^{-2}$. Combined with the low $V_{\mathrm{OC}}$ and low FF, it generates a PCE of only $1 \%$. 

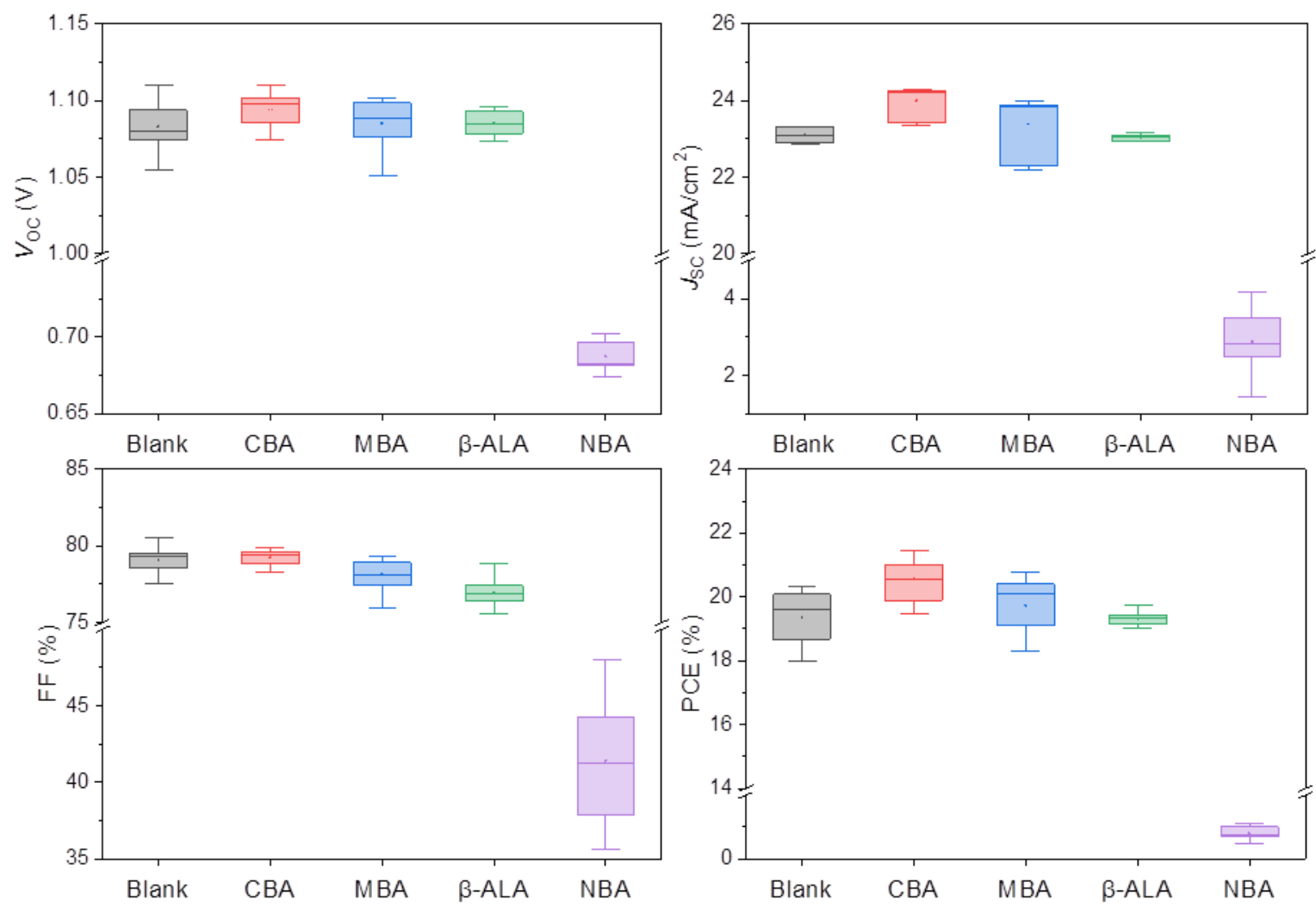

Figure 4. Statistical analysis of the $J-V$ curve parameters of 20 cells from the same batch.

In Table 1 is also reported the hysteresis index (HI). This index is larger for the acid treated samples compared to the blank cell $(\mathrm{HI}=6.6 \%)$. The highest $\mathrm{HI}$ is found for the MBA PSC with $\mathrm{HI}=19.3 \%$. The stabilized efficiency was determined by tracking experiments. The results are gathered in Figure 5a and Figure S4 (Supporting Information). We note that the superior performance of the CBA cells is confirmed with a stabilized PCE of $20.9 \%$ reached after 2 min while the blank cell achieved only a $20.0 \%$ stabilized PCE. We also notice that the systems have a slower response time in the case of the acid-modified cells. For instance, the steady state maximum power was reached after $80 \mathrm{~s}$ for the CBA PSC while it was found after only $20 \mathrm{~s}$ in the case of blank one. More generally, the SAMs modified devices always exhibit a slower rise 
than the blank pristine one (Figure S4, Supporting Information). The rise can be attributed to the re-organization of the interface upon polarization. This re-organization is linked with the mobility of ions in the Cs8FAMA perovskite and to the ionic redistribution. An interesting information is that the different time scale in the tracking curves is related to the hysteresis. The longer is the time to reach the steady state, the higher is the hysteresis in the $J-V$ curve. Also, we have shown elsewhere that the slow electrical phenomena are also related to the low frequency capacitance measured on PSCs. ${ }^{16,44}$
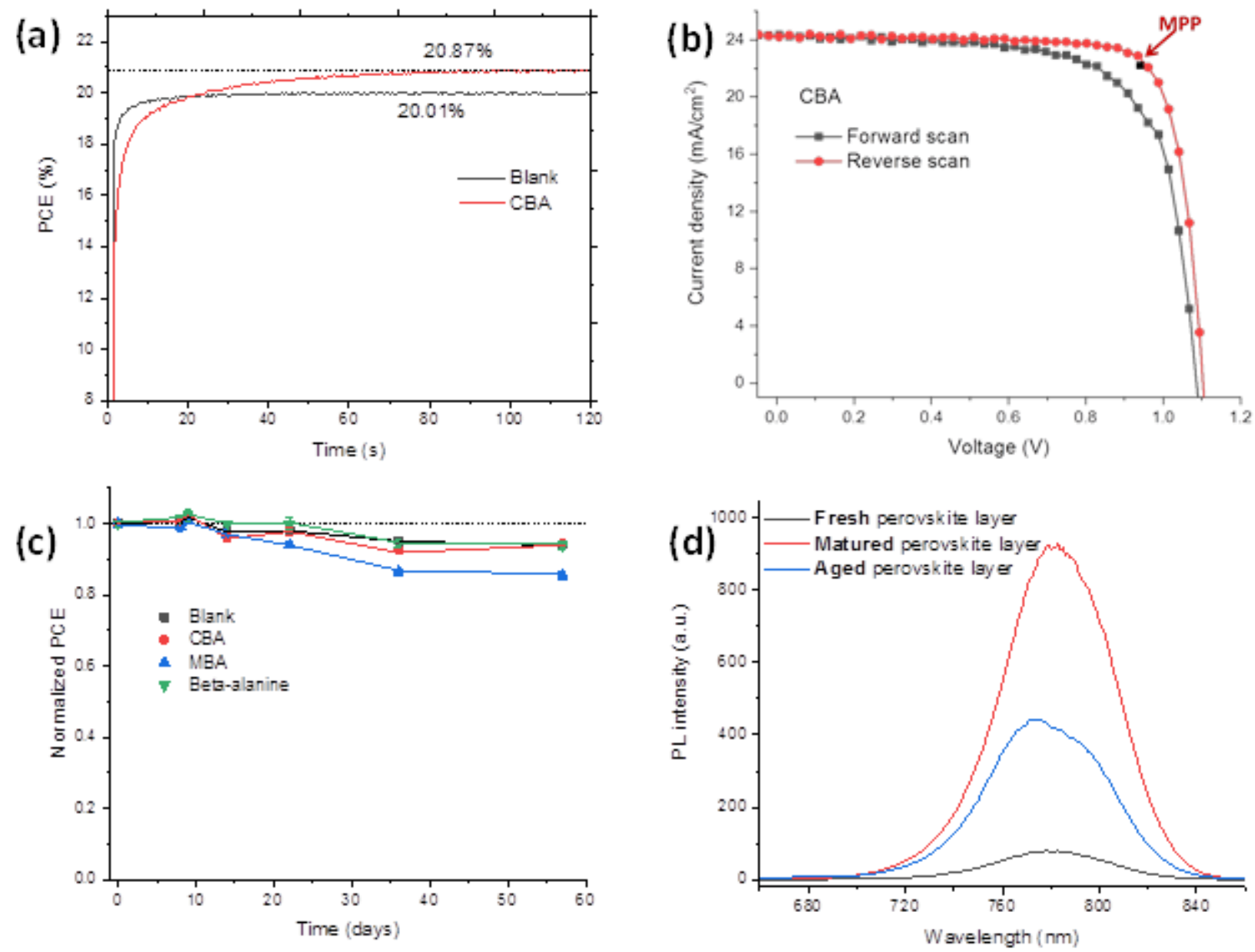

Figure 5. (a) Tracking of the maximum overall power conversion efficiency of the CBA and blank cells. (b) Forward and reverse $J$ - $V$ curves of CBA cell with the stabilized maximum power point (MPP). (c) Stability test of unencapsulated cells treated with various acids. (d) PL emission spectra of fresh, three days matured and 12 days aged Cs8FAMA layer deposited on glass. 
An important question is whether the hysteresis is detrimental for the high steady-state efficiency of our PSCs. In Figure 5c, we have plotted the maximum steady-state power point (MPP) of the CBA cell. This parameter is close to the reverse scan $J-V$ curve. It does not look influenced by the hysteresis. Similarly, for the blank cell and the $\beta$-ALA cell, the MPP is close to the reverse scan $J-V$ curve (Figure S4, Supporting Information). Our data show that in the high efficiency triple cation solar cells, the hysteresis is not a problem for the steady-state efficiency of the device. It corresponds to ionic reorganizations and a larger hysteresis only means that achieving the steady state current will take longer time.

The stability of unencapsulated cells was followed for two months (Figure 5c). The PSCs exhibited a good stability and had a similar evolution. It is concluded that the interface modification is not detrimental for the stability. Because the SAMs are placed under the OIHP layer, no improvement in stability was found. We can note that some groups have successfully implemented the strategy of placing SAMs with hydrophobic properties on top of the OIHP layer to enhance the device stability. ${ }^{30,33}$ Therefore engineering the interfaces of the perovskite on both sides could be a successful strategy to get highly efficient and stable PSCs. In Figure 5c, we can see that the MBA cells were less stable. It can be linked to the larger amount of $\mathrm{PbI}_{2}$ present in the OIHP of these cells as shown by the XRD patterns in Figure 2a.

A more attentive scrutinizing of the evolution curves (Figure 5c) shows that the efficiency of all the devices increased during the first few days. A surprising maturation period is found at the beginning. To elucidate this performance improvement phenomenon, photoluminescence measurements were conducted. Figure $5 \mathrm{~d}$ shows the spectra of a fresh layer and of a three days 
old layer. The PL intensity is about ten times higher after the few days of storage. Therefore, during this maturation step, the structural quality of the HP is improved, defects are annealed/passivated and the radiative recombination increases. Then, when the layer is aged, the PL intensity decreases due to the perovskite degradation (Figure 5d).

\section{Discussion}

We will now discuss the effect of SAMs on the PSC performances. We have shown above that they have no significant influence on the morphology of the perovskite layer, on their crystallinity and on the grain size. Various interfacial modifiers have been tested that cover a wide range of dipole moment by varying their para-substituents and spacers. By periodic DFT modeling, the anchoring of the acids by their carboxy group onto the $\mathrm{TiO}_{2}$ surface has been confirmed and the attachment mode has been found bridging bidentate. ${ }^{40}$ The functional groups will induce different interaction with the perovskite layer and the modifiers will also exhibit molecular dipole moment of various strength and sign. Since the latter parameter is reported to be key in interfacial engineering of opto-electronic devices in several papers, dipole moment values have been investigated by ab-initio periodic DFT calculations. They have been calculated for the isolated molecules $\left(\mu_{\mathrm{i}}\right)$ as well as for the molecules bound to the $\mathrm{TiO}_{2}$ surface. In the latter case, we have been interested in the molecular dipole moment component normal to the surface, noted $\mu_{\perp}$. The effect of the methanol solvent on the adsorber configuration has been taken into account. The values are disclosed in Table S2 (Supporting Information). They were systematically lower than the value for the isolated molecules due to the molecule tilting and to the charge transfer that accompanies the acid binding onto the surface. The value ranged from $0.50 \mathrm{D}(\mathrm{MBA})$ to $2.22 \mathrm{D}(\mathrm{NBA})$. However, the cell performance and $J_{\mathrm{SC}}$ (Table 1) do not follow the order of $\mu_{\perp}$. For instance, CBA and NBA have the same sign for $\mu_{\perp}$, but the former boosts 
the performances, while the latter presents poor efficiency. To get further insight into the dipole moment effect on the PSC functioning, $\mu_{\perp}$ have been calculated by modeling the oxide/CBA/perovskite interface. The model details are developed below. The calculated $\mu_{\perp}$ are gathered in Table S3 (Supporting Information). For CBA, if this parameter is rather high at 1.55 $\mathrm{D}$ for the isolated molecule, it is much less, viz. $0.61 \mathrm{D}$, when the molecule is sandwiched between the two layers. It illustrates that discussion of the dipole moment effect based on data for the isolated modifier molecule, as found in many papers (e.g. references ${ }^{23-26}$ ), is not accurate and must be refined.

The next parameter that must be scrutinized is the quality of the perovskite. The quality of the formed Cs8FAMA layer for various acid-treated $\mathrm{TiO}_{2}$ underlayers was probed by measuring the slow photoluminescence decay of the perovskite which is assigned to the bimolecular recombination. ${ }^{44}$ The absorber was excited at $470 \mathrm{~nm}$ with a diode laser. The curves in Figure S5 (Supporting Information) provide the following decay lifetimes: $183 \mathrm{~ns}, 117 \mathrm{~ns}, 79 \mathrm{~ns}, 64 \mathrm{~ns}$, and $18 \mathrm{~ns}$, for CBA, MBA, blank, $\beta$-ALA and NBA cells, respectively. We found a good correlation between the slow decay time $\left(\tau_{\mathrm{sl}}\right)$ and the cells $J_{\mathrm{SC}}$ : the higher $\tau_{\mathrm{sl}}$, the higher $J_{\mathrm{SC}}$. Actually, this parameter reflects the quality of the OIHP material and high values reflect low quenching phenomena in the bulk. Our data shows that Cs8FAMA formed on the CBA, and in a less extent, on the MBA has a better structural quality than the pristine material.

To further explain the marked enhancement of the cell performance with CBA SAMs, we performed periodic hybrid DFT calculations of the heterostructure. Since band alignment between the perovskite and the oxide is a key point for efficient electron injection in the cell, all calculations have been performed at the computationally-demanding hybrid DFT level. Chloride was supposed to strongly interact with the inorganic framework of the perovskite, creating a 
structural continuity between $\mathrm{TiO}_{2}$ and the perovskite. To validate this hypothesis, an interface model has been built. MAPI was chosen as the perovskite instead of Cs8FAMA since: (i) the former is structurally simpler than the latter, with the different moieties playing the same role in both systems, (ii) the efficiency enhancement has also been proven with CBA in MAPI cells (see Table S1b, Supporting Information). From a structural viewpoint, conclusions obtained for the MAPI-based model should therefore be qualitatively similar to those obtained with a Cs8FAMAbased model. Starting from converged surface models of the oxide and MAPI, a $\mathrm{MAPI} / \mathrm{CBA} / \mathrm{TiO}_{2}$ interface was built. For the oxide part, the building block is a (2x2) supercell model of the anatase $\mathrm{TiO}_{2}$ most stable(101) surface with a thickness of 8 slabs layers (8 O-Ti-O trilayers), accounting for 96 atoms with lattice parameters $a=14.981 \AA, b=11.088 \AA$ and $\gamma=$ $109.7^{\circ}$. For MAPI, a (110) surface orientation, MAI-terminated, was considered as this surface is known to be stable ${ }^{45}$ and the MAI termination can be expected to bind more easily with a functionalized oxide surface than the $\mathrm{PbI}_{2}$ termination. A slab with 3-PbI layers was cut out from the $\mathrm{MAPbI}_{3}$ bulk system (space group I4/mcm), with a, b and $\gamma$ lattice parameters of 12.343 $\AA, 12.555 \AA$ and $90.0^{\circ}$, resulting in a rather large cell parameter mismatch between the $\mathrm{TiO}_{2}$ and MAPI lattices. The interface was created by using CBA as a linker: the carboxylate part was used to bind to $\mathrm{TiO}_{2}$ in a bridging bidentate mode, while $\mathrm{Cl}$ atoms were oriented towards the $\mathrm{Pb}$ atoms of MAPI close to the $\mathrm{TiO}_{2}$ substrate, and $\mathrm{Pb}-\mathrm{Cl}$ bonds were created by substituting all $\mathrm{I}^{-}$of the last layer of the MAPI surface with $\mathrm{Cl}$ atoms. To ensure charge neutrality of the resulting unit cell, $\mathrm{H}^{+}$of the last layer of MA moieties of MAPI were then removed. Finally, cell parameters matching was ensured by modifying the MAPI lattice to match the cell parameters of the $\mathrm{TiO}_{2}$ supercell. The resulting interface model had P1 symmetry, with 328 atoms and 3876 atomic orbitals. The lattice was then fully-relaxed, and all atoms were allowed to relax except for the 6 
bottom layers of the $\mathrm{TiO}_{2}$ substrate which were kept fixed to their relaxed positions in the clean supercell.

(a)

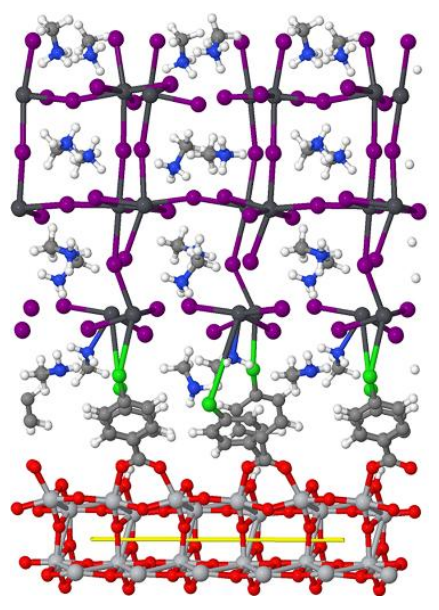

(b)

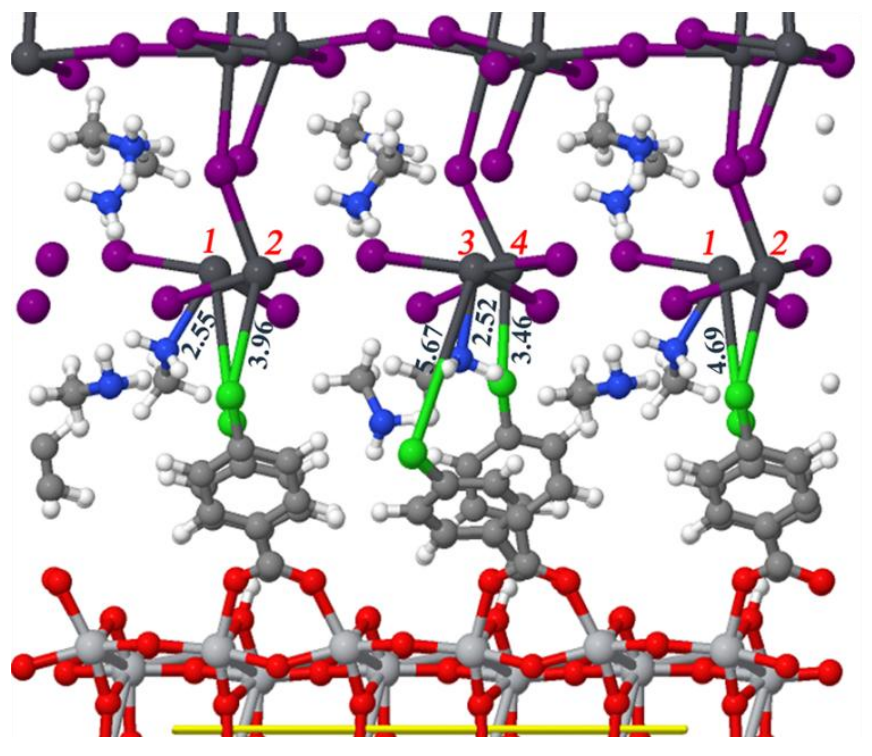

Figure 6. Schematic drawing of the MAPI/CBA/TiO ${ }_{2}$ interface unit cell. (a) Whole system; (b) zoomed portion of the MAPI/CBA/TiO 2 binding. Data in black correspond to distances (in $\AA$ ), while the red ones correspond to atom numbers mentioned in the text. The solid yellow line represents the unit cell. Red, light grey, white, green, purple, dark grey, blue and grey spheres correspond to $\mathrm{O}, \mathrm{Ti}, \mathrm{H}, \mathrm{Cl}, \mathrm{I}, \mathrm{Pb}, \mathrm{N}$ and $\mathrm{C}$ atoms, respectively.

Figures $6 \mathrm{a}$ and $6 \mathrm{~b}$ show the interface structure after geometry optimization. The left figure is the whole interface model and the right one focuses on the interfacial region. The optimized a and b cell parameters for the obtained structure are $14.821 \AA$ and $11.003 \AA$, respectively, and the $\gamma$ angle is $108.0^{\circ}$. These values are close to those of the $\mathrm{TiO}_{2}$ supercell considered to build the model, with only a small shrinking after relaxation. Based on the data reported in Figure 6b, we can conclude that the interface obtained between MAPI, CBA and $\mathrm{TiO}_{2}$ is mainly ensured by 
both $\mathrm{Ti}-\mathrm{O}$ and $\mathrm{Pb}-\mathrm{Cl}$ bonds. Indeed, a bridging bidentate mode is involved between the carboxylate group of $\mathrm{CBA}$ and $\mathrm{TiO}_{2}$, while strongly distorted $\mathrm{PbI}_{5} \mathrm{Cl}$ octahedra can be evidenced between MAPI and CBA. It should however be noted that the $\mathrm{Cl}$ atoms and deprotonated $\mathrm{CH}_{3} \mathrm{NH}_{3}{ }^{+}$groups have a competitive binding to the $\mathrm{Pb}$ atoms. For instance, $\mathrm{Pb}$ atoms 2 and 4 bind to neighboring $\mathrm{Cl}$ atoms with distances close to $3.5 \AA$. On the other hand, $\mathrm{Pb}$ atoms 1 and 3 present larger distances with $\mathrm{Cl}$ (around $4.6 \AA$ ) than with the $\mathrm{NH}_{2}$ groups of the deprotonated $\mathrm{CH}_{3} \mathrm{NH}_{3}{ }^{+}$moieties (around $2.5 \AA$ ). It should also be noted that the four CBA ligands in the interface unit cell have tilting angles with respect to the $\mathrm{c}$ axis of $30.0^{\circ}, 38.6^{\circ}, 38.6^{\circ}$ and $46.9^{\circ}$. These values are generally larger than the $30.3^{\circ}$ value obtained for the adsorption of CBA on $\mathrm{TiO}_{2}$ anatase (101), indicating that the CBA ligands can lay on the $\mathrm{TiO}_{2}$ surface with favorable $\mathrm{H}^{+} / \pi$ interactions in order to act as efficient linkers for the interface formation.

From the computed data, the presence of a halogen substituent on the ligand $(\mathrm{Cl}$ in the case of CBA) seems an important requirement for a stable bonding with the perovskite. On the other hand, the relatively fixed conformation of the CBA ligand imposed by its binding to the $\mathrm{TiO}_{2}$ surface built a favorably organized $\mathrm{CBA}-\mathrm{TiO}_{2}$ interface for the binding of perovskite. This is probably not the case when more flexible ligands are chosen (see the 4-nitrobenzoic acid (NBA) case for instance).

\section{Conclusions}

In summary, we have demonstrated that the engineering of the interface between perovskite and titania is important to get highly efficient perovskite solar cells. By using this strategy, we have been able to prepare PSCs reaching a PCE of 21.3\% (stabilized at 20.9\%). We have shown that in high efficiency triple cation PSCs, the chloride functionalized benzoic acid molecule 
provides a significant beneficial effect. CBA forms a $\mathrm{SAM}$ at the $\mathrm{TiO}_{2}$ surface and is attached in a bridging bidentate mode. This interlayer did not change the perovskite film morphology and crystallinity. We have also shown that its effect cannot be due to the band energy level management by its molecular dipole moment, moment which is reduced in a large extent while sandwiched between $\mathrm{TiO}_{2}$ and the perovskite. Actually, our experimental and theoretical investigations emphasize that CBA SAMs at the oxide/perovskite interface is beneficial for the structural continuity, the trap state reduction and for the global quality of the perovskite. We show that the presence of a halogen substituent on the ligand ( $\mathrm{Cl}$ in the case of $\mathrm{CBA})$ is a significant requirement to establish a stable bonding with the perovskite. We point out that the interfacial chemical interactions are important to consider for the design of highly efficient interfaces and that the relatively fixed conformation of the CBA ligand, imposed by its binding to the $\mathrm{TiO}_{2}$ surface, built a favorably organized $\mathrm{CBA}-\mathrm{TiO}_{2}$ interface for the binding of perovskite.

\section{Experimental section}

The fluorine-doped $\mathrm{SnO}_{2}$ (FTO) substrates (TEC 7 from Pilkington) were etched and pattern as described elsewhere. ${ }^{40}$ The $\mathrm{TiO}_{2}$ blocking layer was deposited as in Ref. ${ }^{40}$. The meso- $\mathrm{TiO}_{2}$ nanoparticulate layer preparation is described in $\mathrm{Refs}^{40,44,46}$. The mesoporous $\mathrm{TiO}_{2}$ layer surface was modified by adsorbing SAMs of 4-chlorobenzoic acid (CBA), 4-methoxy benzoic acid (MBA); 4-nitro benzoic acid (NBA) and $\beta$-alanine ( $\beta$-ALA) as described in Ref. ${ }^{40}$. Their molecular structures are shown in Figure 1. It is noteworthy that aside these four acids, we also evaluated, in a preliminary test, two other benzoic acid derivatives, namely the 4-bromobenzoic acid (BrBA) and the 4-aminobenzoic acid (ACA). In Table S5, the results averaged for several cells, show a superior PCE for BrBA-based cells compared to the blank ones but inferior to 
CBA-based devices. Table S5 also shows a PCE lower than the blank cells for the ABA-based devices. These acids were not further investigated.

A precursor solution of $\mathrm{Cs}_{0.08} \mathrm{FA}_{0.80} \mathrm{MA}_{0.12} \mathrm{~Pb}\left(\mathrm{I}_{0.88} \mathrm{Br}_{0.12}\right)_{3}$ was prepared by mixing $179 \mathrm{mg}$ of formamidinium iodide (FAI), $17.4 \mathrm{mg}$ of methylammonium bromide (MABr), $27.0 \mathrm{mg}$ of CsI, $548 \mathrm{mg}$ of $\mathrm{PbI}_{2}$ and $57.1 \mathrm{mg}$ of $\mathrm{PbBr}_{2}$, in a solvent mixture of $220 \mu \mathrm{L}$ DMSO and $780 \mu \mathrm{L} \mathrm{DMF}$. The solution was stirred for a minimum of 3-4 $\mathrm{h}$ at room temperature in the glovebox before use. $^{47,48} 42 \mu \mathrm{L}$ of this solution was placed on top of the substrates. A two-step spin-coating program was employed: first spinning at $1000 \mathrm{rpm}$ for $10 \mathrm{~s}$ and then at $6000 \mathrm{rpm}$ for $30 \mathrm{~s} .100$ $\mu \mathrm{L}$ of chlorobenzene was dripped $20 \mathrm{~s}$ after the starting of the spinning routine. The films were then annealed at $105^{\circ} \mathrm{C}$ for $1 \mathrm{~h}$.

The solution of Spiro-OMeTAD (Borun New Material Technology) was prepared as in Ref. $^{44}$ and it was deposited by spin-coating. Perovskite and HTM layers were fabricated in a dry air glovebox with $\mathrm{RH}<10 \%$. Finally, the gold back contact was formed on the Spiro-OMeTAD layer by thermal evaporation. The contact thickness was 70-80 nm.

The $J$ - $V$ curves were recorded as described in $\operatorname{Refs}^{44,49,50}$. The tracking experiments were performed under ambient conditions. The current was followed at the voltage of the maximum power. For the stability tests, the cells were stored in a $\mathrm{N}_{2}$ filled glovebox and kept under ambient lighting between the PV characterizations.

The XRD patterns of the OIHP films were measured with a PANanalytical X-Pert highresolution X-ray diffractometer (XRD) and as described in Ref. ${ }^{44}$. The absorbance spectra were recorded by a Cary $5000 \mathrm{UV}$-Vis-NIR spectrophotometer. A glass/FTO/TiO $/ m p-\mathrm{TiO}_{2}$ sample was used as the baseline. The photoluminescence spectra were recorded by a Cary Eclipse fluorescence spectrophotometer. The sample morphologies were examined with a high resolution 
Ultra 55 Zeiss FEG field-emission scanning electron microscope (FE-SEM) in the in-lens mode.

The full experimental details are provided in the Supporting Information.

\section{ASSOCIATED CONTENT}

\section{Supporting Information}

The Supporting Information is available free of charge on the ACS Publications website at DOI: 10.1021/acsami.XXXXXX.

Computational details, SEM cross-sectional view of a PSC and top views the $m p-\mathrm{TiO}_{2}$ layer, FTIR investigation of the SAMs formation, Direct bandgap determination of Cs8FAMA perovskite, $J-V$ curves and efficiency tracking of the PSCs, Averaged $J-V$ parameters of Cs8FAM and MAPI cells, Calculated dipole moments and molecules tilt angles, Time-correlated single photon counting decay curves and comparison of blank, CBA, BrBA and ABA PSCs.

\section{AUTHOR INFORMATION}

\section{Corresponding Author}

*Thierry Pauporté

\section{Present Addresses}

$\dagger$ Chimie ParisTech, PSL Research University, CNRS, Institut de Recherche de Chimie Paris

(IRCP) 11 rue P. et M. Curie, F-75005 Paris, France.

E-mail: thierry.pauporte@ chimieparistech.psl.eu.

\section{ACKNOWLEDGMENTS}


T.Z. and J.S. thank the CSC-Paristech and CSC program for Ph.D scholarship. The ANR agency is acknowledged for financial support (Moreless project ANR-18-CE05-0026). Dr. G. Lefèvre (IRCP, Chimie-Paristech, France) is acknowledged for permitting the FTIR measurements and for discussion. Mr J. Liu (INSP, Sorbonne University, France) is acknowledged for TCSPC measurements. This work was supported by the ITN COSINE to I.C. (GA 765739). J.S., F.L. and I.C acknowledge the use of computational resources at Très Grand Centre de Calcul (TGCC) provided by GENCI through project A0050810135.

\section{REFERENCES}

(1) Veldhuis, S. A.; Boix, P. P.; Yantara, N.; Li, M.; Sum, T. C.; Mathews, N.; Mhaisalkar, S. G. Perovskite Materials for Light-Emitting Diodes and Lasers. Adv. Mater. 2016, 28, 6804-6834.

(2) Kim, H. S.; Lee, C. R.; Im, J. H.; Lee, K. B.; Moehl, T.; Marchioro, A.; Moon, S. J.; HumphryBaker, R.; Yum, J. H.; Moser, J. E.; Grätzel, M. Lead Iodide Perovskite Sensitized All-Solid-State Submicron Thin Film Mesoscopic Solar Cell with Efficiency Exceeding 9\%. Sci. Rep. 2012, 2, 591.

(3) Lee, M. M.; Teuscher, J.; Miyasaka, T.; Murakami, T. N.; Snaith, H. J. Efficient Hybrid Solar Cells Based on Meso-Superstructured Organometal Halide Perovskites. Science 2012, 338, 643-647.

(4) Liu, M.; Johnston, M. B.; Snaith, H. J. Efficient Planar Heterojunction Perovskite Solar Cells by Vapour Deposition. Nature 2013, 501, 395-398.

(5) Burschka, J.; Pellet, N.; Moon, S. J.; Humphry-Baker, R.; Gao, P.; Nazeeruddin, M. K.; Grätzel, M. Sequential Deposition as A Route to High-Performance Perovskite-Sensitized Solar Cells. Nature 2013, 499, 316-319.

(6) Zhang, J.; Barboux, P.; Pauporté, T. Electrochemical Design of Nanostructured ZnO Charge Carrier Layers for Efficient Solid-State Perovskite-Sensitized Solar Cells. Adv. Energy Mater. 2014, 4, 1400932. 
(7) Nie, W.; Tsai, H.; Asadpour, R.; Blancon, J. C.; Neukirch, A. J.; Gupta, G.; Crochet, J. J.; Chhowalla, M.; Tretiak, S.; Alam, M. A.; Wang, H. L. High-Efficiency Solution-Processed Perovskite Solar Cells with Millimeter-Scale Grains. Science 2015, 347, 522-525.

(8) Zhang, J.; Juárez-Pérez, E. J.; Mora-Seró, I.; Viana, B.; Pauporté, T. Fast and Low Temperature Growth of Electron Transport Layers for Efficient Perovskite Solar Cells. J. Mater. Chem. A. 2015, $3,4909-4915$.

(9) Zhang, J.; Pauporté, T. Effects of Oxide Contact Layer on the Preparation and Properties of $\mathrm{CH}_{3} \mathrm{NH}_{3} \mathrm{PbI}_{3}$ for Perovskite Solar Cell Application. J. Phys. Chem. C 2015, 119, 14919-14928.

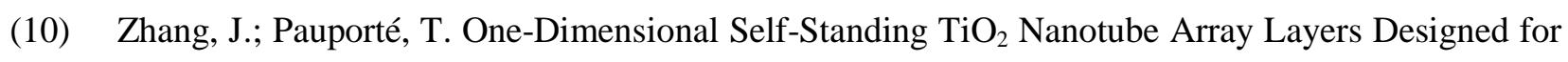
Perovskite Solar Cell Applications. ChemPhysChem 2015, 16, 2836-2841.

(11) Tu, Y.G.; Xu, G.N.; Yang, X.Y.; Zhang Y.F.; Li, Z.J.; Su R.; Luo D.Y.; Yang, W.Q.; Miao, Y.; Cai R.; Jiang L.H.; Du, X.W.; Yang, Y.C.; Liu, Q.S.; Gao, Y.; Zhao, S.; Huang, W.; Gong, Q.H.; Zhu, R. Mixed-Cation Perovskite Solar Cells in Space. Sci. China-Phys. Mech. Astron. 2019, 62, 974221-1- 974221-4.

(12) Yang, W. S.; Park, B. W.; Jung, E. H.; Jeon, N. J.; Kim, Y. C.; Lee, D. U.; Shin, S. S.; Seo, J.; Kim, E. K.; Noh, J. H.; Seok, S. I. Iodide Management in Formamidinium-Lead-Halide-Based Perovskite Layers for Efficient Solar Cells. Science 2017, 356, 1376-1379.

Leblanc, A.; Mercier, N.; Allain, M.; Dittmer, J.; Fernandez, V.; Pauporté, T.; Lead-and IodideDeficient $\left(\mathrm{CH}_{3} \mathrm{NH}_{3}\right) \mathrm{PbI}_{3}$ (d-MAPI): The Bridge between 2D and 3D Hybrid Perovskites. Angew. Chem., Int. Ed. 2017, 56, 16067-16072.

(14) Wang, P.; Ulfa, M.; Pauporté, T. Effects of Perovskite Monovalent Cation Composition on the High and Low Frequency Impedance Response of Efficient Solar Cells. J. Phys. Chem. C 2018, 122, 1973-1981.

(15) NREL chart (2019) https://www.nrel.gov/pv/cell-efficiency.html 
(16) Wang, P.; Shao, Z.; Ulfa, M.; Pauporté, T.; Insights into the Hole Blocking Layer Effect on the Perovskite Solar Cell Performance and Impedance Response. J. Phys. Chem. C 2017, 121, 91319141.

(17) Qiao, R.; Zuo, L. Self-Assembly Monolayers Boosting Organic-Inorganic Halide Perovskite Solar Cell Performance. J. Mater. Res. 2018, 33, 387-400.

(18) Hu, T.; Becker, T.; Pourdavoud, N.; Zhao, J.; Brinkmann, K. O.; Heiderhoff, R.; Gahlmann, T.; Huang, Z.; Olthof, S.; Meerholz, K.; Többens, D. Indium-Free Perovskite Solar Cells Enabled by Impermeable Tin-Oxide Electron Extraction Layers. Adv. Mater. 2017, 29, 1606656.

(19) Olthof, S.; Meerholz, K. Substrate-Dependent Electronic Structure and Film Formation of MAPbI ${ }_{3}$ Perovskites. Sci. Rep. 2017, 7, 40267.

(20) Yang, Z; Dou, J.J.; Wang, M.Q. Interface Engineering in n-i-p Metal Halide Perovskite Solar Cells. Sol. RRL 2018,2, 1800177.

(21) Lim, K.G.; Ahn, S.; Lee, T.W. Energy level alignment of dipolar interface layer in organic and hybrid perovskite solar cells. J. Mater. Chem. C 2018, 6, 2915-2924.

(22) Choi, K; Choi, H.; Min, J.; Kim, T.; Kim, D.; Son, S.Y.; Kim, G.W.; Choi, J.; Park, T.; A Short Review on Interface Engineering of Perovskite Solar Cells: A Self-Assembled Monolayer and Its Roles. Sol. RRL 2019, 1900251.

(23) Li, B.; Chen, Y.; Liang, Z.; Gao, D.; Huang, W. Interfacial Engineering by Using Self-Assembled Monolayer in Mesoporous Perovskite Solar Cell. RSC Adv. 2015, 5, 94290.

(24) Zuo, L.; Gu, Z.; Ye, T.; Fu, W.; Wu, G.; Li, H; Chen, H. Enhanced Photovoltaic Performance of $\mathrm{CH}_{3} \mathrm{NH}_{3} \mathrm{PbI}_{3}$ Perovskite Solar Cells Through Interfacial Engineering Using Self-Assembling Monolayer. J. Am. Chem. Soc. 2015, 137, 2674-2679.

(25) Azmi, R.; Hadmojo, W. T.; Sinaga, S.; Lee, C. L.; Yoon, S. C.; Jung, I. H. Jang, S. Y. HighEfficiency Low-Temperature ZnO Based Perovskite Solar Cells Based on Highly Polar, Nonwetting Self-Assembled Molecular Layers. Adv. Energy Mater. 2017, 7, 1701683. 
(26) Wang, Q.; Chueh, C. C.; Zhao, T.; Cheng, J.; Eslamian, M.; Choy, W. C.; Jen, A. K. Y. Effects of Self-Assembled Monolayer Modification of Nickel Oxide Nanoparticles Layer on the Performance and Application of Inverted Perovskite Solar Cells. ChemSusChem 2017, 10, 3794-3803.

(27) Will, J.; Hou, Y.; Scheiner, S.; Pinkert, U.; Hermes, I. M.; Weber, S. A.; Hirsch, A.; Halik, M.; Brabec, C.; Unruh, T. Evidence of Tailoring the Interfacial Chemical Composition in Normal Structure Hybrid Organohalide Perovskites by A Self-Assembled Monolayer. ACS Appl. Mater. Interfaces 2018, 10, 5511-5518.

(28) Yalcin, E.; Can, M.; Rodriguez-Seco,; C., Aktas, E.; Pudi, R.; Cambarau, W.; Demic, S.; Palomares, E. Semiconductor Self-Assembled Monolayers as Selective Contacts for Efficient PiN Perovskite Solar Cells. Energy Environ. Sci. 2019, 12, 230-237.

(29) Gu, Z.; Zuo, L.; Larsen-Olsen, T. T.; Ye, T.; Wu, G.; Krebs, F. C.; Chen, H. Interfacial Engineering of Self-Assembled Monolayer Modified Semi-Roll-to-Roll Planar Heterojunction Perovskite Solar Cells on Flexible Substrates. J. Mater. Chem. A 2015, 3, 24254-24260.

(30) Cao, J.; Yin, J.; Yuan, S.; Zhao, Y.; Li, J.; Zheng, N. Thiols as Interfacial Modifiers to Enhance the Performance and Stability of Perovskite Solar Cells. Nanoscale 2015, 7, 9443.

Lu, J.; Lin, X.; Jiao, X.; Gengenbach, T.; Scully, A. D.; Jiang, L.; Tan, B.; Sun, J.; Li, B.; Pai, N.; Bach, U. Interfacial Benzenethiol Modification Facilitates Charge Transfer and Improves Stability of cm-Sized Metal Halide Perovskite Solar Cells with up to 20\% Efficiency. Energy Environ. Sci. 2018, 11, 1880-1889.

Wang, Q.; Dong, Q.; Li, T.; Gruverman, A.; Huang, J. Thin Insulating Tunneling Contacts for Efficient and Water-Resistant Perovskite Solar Cells. Adv. Mater. 2016, 28, 6734.

Zhang, J.; Hu, Z.; Huang, L.; Yue, G.; Liu, J.; Lu, X.; Hu, Z.; Shang, M.; Han, L.; Zhu, Y. Bifunctional Alkyl Chain Barriers for Efficient Perovskite Solar Cells. Chem. Commun. 2015, 51, 7047. 
(34) Sundaraganesan, N.; Anand, B.; Meganathan, C.; Joshua, B. D. FT-IR, FT-Raman Spectra and ab Initio HF, DFT Vibrational Analysis of p-Chlorobenzoic Acid. Spectrochim. Acta, Part A 2008, 69, 871.

(35) Luo, X.; Shen, J.; Zhao, X.; Wang, Z.; Wu, B.; Li, L.; Jiang, S.; Zhou, X. Synthesis, Structure and Fluorescence of Er (III) Complexes with Benzoic Acid and 4-Chlorobenzoic Acid. Inorg. Chim. Acta 2016, 446, 169.

(36) Badilescu, S.; Ashrit, P. V.; Truong, V. V. Enhanced Infrared Attenuated-Total-Reflection Spectra of p-Nitrobenzoic Acid with Ag Films. Appl. Phys. Lett. 1988, 52, 1551.

(37) Soo, H.; Chang, H.; Kim, H.; Kim, K. Diffuse Reflectance Infrared Spectra of 4-Nitrobenzoic Acid and 4-Cyanobenzoic Acid Self-Assembled on Fine Silver Particles. Appl. Spectrosc. 1998, 52, $1047-1052$.

(38) Shao, S.; Liu, F.; Fang, G.; Zhang, B.; Xie, Z.; Wang, L. Enhanced Performances of Hybrid Polymer Solar Cells with p-Methoxybenzoic Acid Modified Zinc Oxide Nanoparticles as an Electron Acceptor. Org. Electron. 2011, 12, 641.

(39) Palafox, M. A.; Gil, M.; Nunez, J. L. Spectroscopy of p-Methoxybenzoic Acid: an AM1 and ab Initio Study. Appl. Spectrosc. 1994, 48, 27-36.

(40) Zhu, T.; Su, J.; Alvarez, J.; Lefèvre, G.; Labat, F.; Ciofini, I.; Pauporté, T. Response Enhancement of Self-Powered Visible-Blind UV Photodetectors by Nanostructured Heterointerface Engineering. Adv. Funct. Mater. 2019, 29, 1903981.

(41) Pauporté, T.; Yoshida, T.; Cortès, R.; Froment, M.; Lincot D. Electrochemical Growth of Epitaxial Eosin/ZnO Hybrid Films. J. Phys. Chem. B, 2003, 107, 10077-10082.

(42) Huang, Y.; Li, L.; Liu, Z.; Jiao, H.; He, Y.; Wang, X.; Zhu, R.; Wang, D.; Sun, J.; Chen, Q.; Zhou, H. the Intrinsic Properties of $\mathrm{FA}_{(1-\mathrm{x})} \mathrm{MA}_{\mathrm{x}} \mathrm{PbI}_{3}$ Perovskite Single Crystals. J. Mater. Chem. A 2017, $5,8537-8544$. 
(43) Zuo, L.; Chen, Q.; De Marco, N.; Hsieh, Y. T.; Chen, H.; Sun, P.; Chang, S. Y.; Zhao, H.; Dong, S.; Yang, Y. Tailoring the Interfacial Chemical Interaction for High-Efficiency Perovskite Solar Cells. NanoLett. 2017, 17, 269-275.

(44) Ulfa, M.; Wang, P.; Zhang, J.; Liu, J.; de Marcillac, W. D.; Coolen, L.; Peralta, S.; Pauporté, T. Charge Injection and Electrical Response in Low-Temperature $\mathrm{SnO}_{2}$-Based Efficient Perovskite Solar Cells. ACS Appl. Mater. Interfaces 2018, 10, 35118-35128.

(45) Haruyama, J.; Sodeyama, K.; Han, L.; Tateyama, Y. Termination Dependence of Tetragonal $\mathrm{CH}_{3} \mathrm{NH}_{3} \mathrm{PbI}_{3}$ Surfaces for Perovskite Solar Cells. J. Phys. Chem. Lett. 2014, 5, 2903-2909.

(46) Ulfa, M.; Wang, P.; Shao, Z.; Viana, B.; Pauporté, T. Proc. SPIE 2018, 10533, 105332R1105332R10.

(47) Nazeeruddin, M. K.; Braukyla, T.; Xia, R.; Daskeviciene, M.; Malinauskas, T.; Gruodis, A.; Jankauskas, V.; Roldán-Carmona, C.; Momblona, C.; Getautis, V.; Fei, Z. Inexpensive Hole Transporting Materials Derived from Tröger's Base Afford Efficient and Stable Perovskite Solar Cells. Angew. Chem. Int. Ed. 2019, 58, 11266-11272.

(48) Xia, R.; Fei, Z.; Drigo, N.; Bobbink, F. D.; Huang, Z.; Jasiūnas, R.; Franckevičius, M.; Gulbinas, V.; Mensi, M.; Fang, X.; Roldán-Carmona, C. Retarding Thermal Degradation in Hybrid Perovskites by Ionic Liquid Additives. Adv. Funct. Mater. 2019, 29, 1902021.

(49) Guérin, V. M.; Elias, J.; Nguyen, T.T.; Philippe, L.; Pauporté, T. Ordered Networks of ZnONanowire Hierarchical Urchin-Like Structures for Improved Dye-Sensitized Solar Cells. Phys. Chem. Chem. Phys. 2012, 14, 12948-12955.

(50) Magne, C.; Dufour, F.; Labat, F.; Lancel, G.; Durupthy, O.; Cassaignon, S.; Pauporté, T. Effects of $\mathrm{TiO}_{2}$ Nanoparticle Polymorphism on Dye-Sensitized Solar Cell Photovoltaic Properties. $J$. Photochem. Photobiol. A 2012, 232, 22-31. 
TOC Graphic

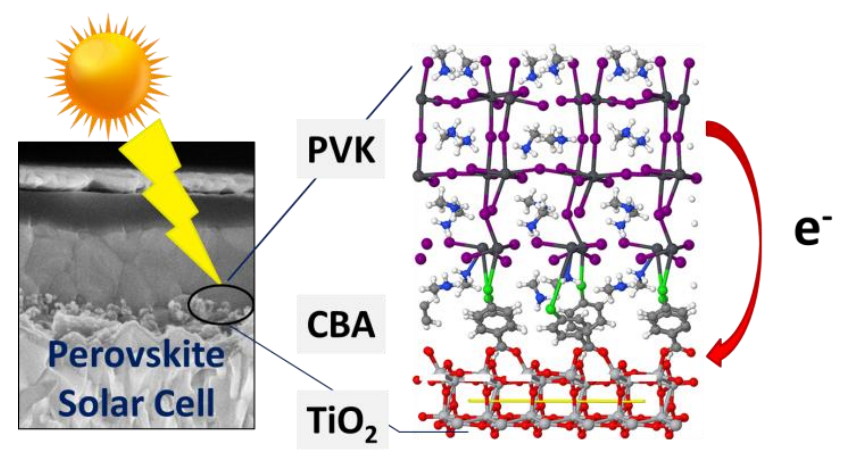

